\title{
Connection between Eurasian and North Atlantic Climate Anomalies and Natural Variations in the Atlantic Thermohaline Circulation Based on Long-Term Model Calculations
}

\author{
Corresponding Member of the RAS I. I. Mokhov ${ }^{a}$, V. A. Semenov ${ }^{a}$, V. Ch. Khon ${ }^{a}$, \\ M. Latif ${ }^{b}$, and E. Roeckner ${ }^{c}$
}

Received November 1, 2007

DOI: $10.1134 / \mathrm{S} 1028334 \mathrm{X} 08030331$

We obtained estimates of the correlation between regional characteristics of the climate in Eurasia and the North Atlantic and the Atlantic thermohaline circulation (ATHC) based on the results of calculations using the ocean-atmosphere global climate model (OAGCM) without external forcing (reference numerical experiment) for the period of $500 \mathrm{yr}$. The regions of statistically significant correlation between the ATHC variations in a few decades with the anomalies of surface air temperature, pressure at sea level, and precipitation in different seasons were distinguished. The most significant correlation was found in the winter period. A correlation was also found between the ATHC and the intensity of the Iceland minimum of the atmospheric action center (AC) [1], which has a strong influence on the weather conditions in Europe.

The Atlantic thermohaline circulation, which shows a large-scale North Atlantic meridional overturning circulation (NAMOC) and represents a part of the global $3 \mathrm{D}$ oceanic current (conveyor belt) [2, 3], plays an important role in heat transfer to high latitudes of the Northern Hemisphere. The intensity of the ATHC shows strong long-period fluctuations accompanied by anomalies in the ocean surface temperature (OST) in the North Atlantic [4] and variations in the area of the Arctic ice cover [5]. This fact evidences the existence of

\footnotetext{
${ }^{a}$ Oboukhov Institute of Atmospheric Physics, Russian Academy of Sciences, Pyzhevskii per. 3, Moscow, 119017 Russia; e-mail: mokhov@ifaran.ru

${ }^{b}$ Leibniz Institute of Marine Sciences at the ChristianAlbrechts University of Kiel, Düsternbrooker Weg 20, Kiel 24105, Germany

${ }^{c}$ Max Plank Institute for Meteorology, Bundesstrasse 53, Hamburg, 20146 Germany
}

a potential correlation between the long-period ATHC variability and climatic regimes in Eurasia and the Arctic region [6-8].

According to the model estimates, the global warming caused by anthropogenic influence [9] can lead to significant variations in the intensity of the ATHC. Possible variations in the oceanic thermohaline circulation and their regional consequences are pressing issues of climatic research. An increase in the surface temperature and precipitation in the Arctic region should decrease salinity and density in the surface layer of the Arctic Ocean and Arctic seas. This phenomenon is intensified by melting of sea ice and an increase in the discharge of rivers into the Arctic basin $[10,11]$. As a result, the stability of the upper oceanic layer should increase as the high-latitude convective processes and intensity of the NAMOC decrease (with a corresponding variation in the location and weakening of the Gulf Stream as one of the components of the ATHC). This can strongly influence regional peculiarities of the climate at high and mid-latitudes of the Northern Hemisphere and, in particular, of the European climate [9].

In this work, we analyze the monthly mean data on surface temperature $T$, pressure at sea level $P$, and precipitation $R$ obtained in the numerical GCM ECHAM5/MPI-OM experiment with a duration of 500 model years without account for external forcing on the climate (the concentration of greenhouse gases and aerosols in the atmosphere and the value of the solar constant were not changed and corresponded to the mean present-day regime). The intensity of the ATHC was characterized by the annual mean values of the NAMOC at $30^{\circ} \mathrm{N}$.

The atmospheric model ECHAM5/MPI-OM has T42 spectral resolution $\left(\sim 2.8^{\circ}\right.$ of latitude/longitude) and 19 vertical levels (up to 10 mbar). The oceanic 
(a)

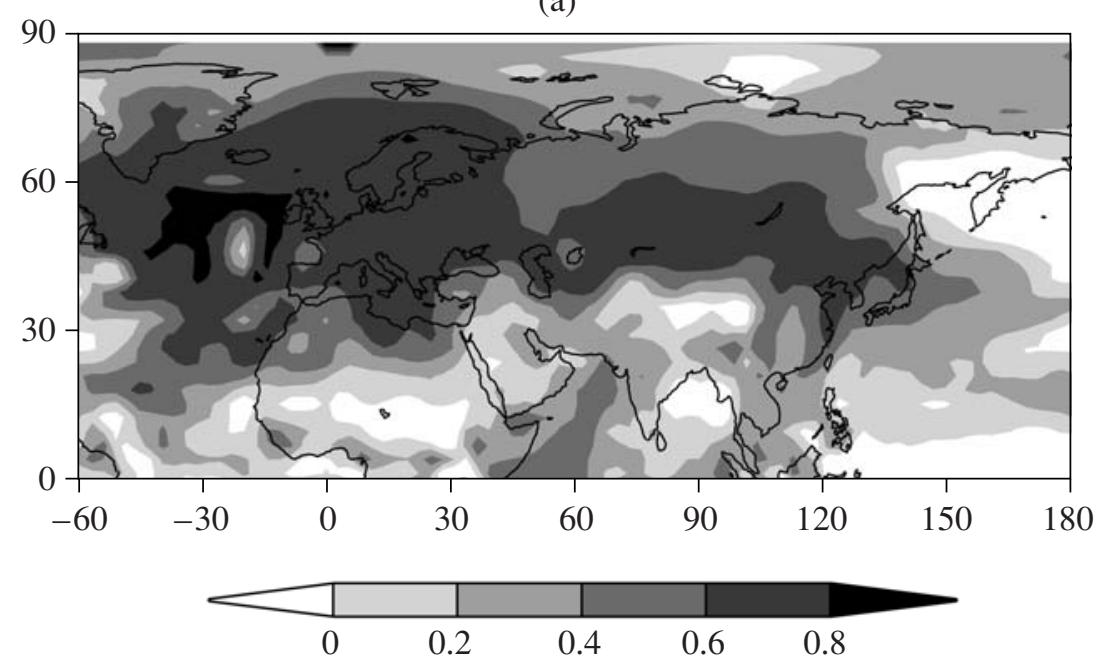

(b)

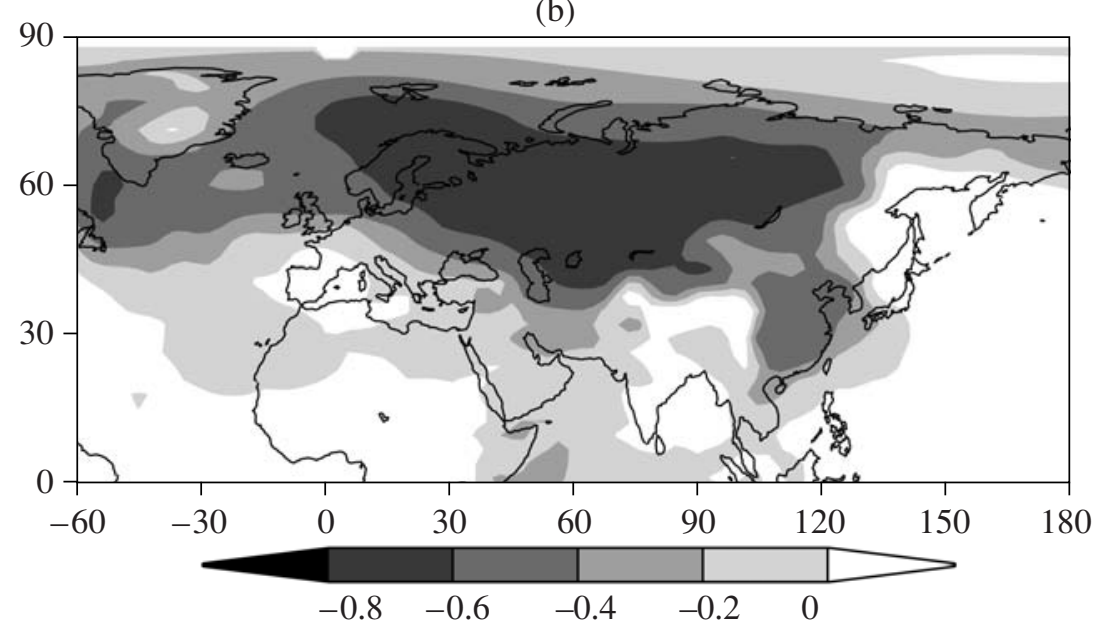

(c)

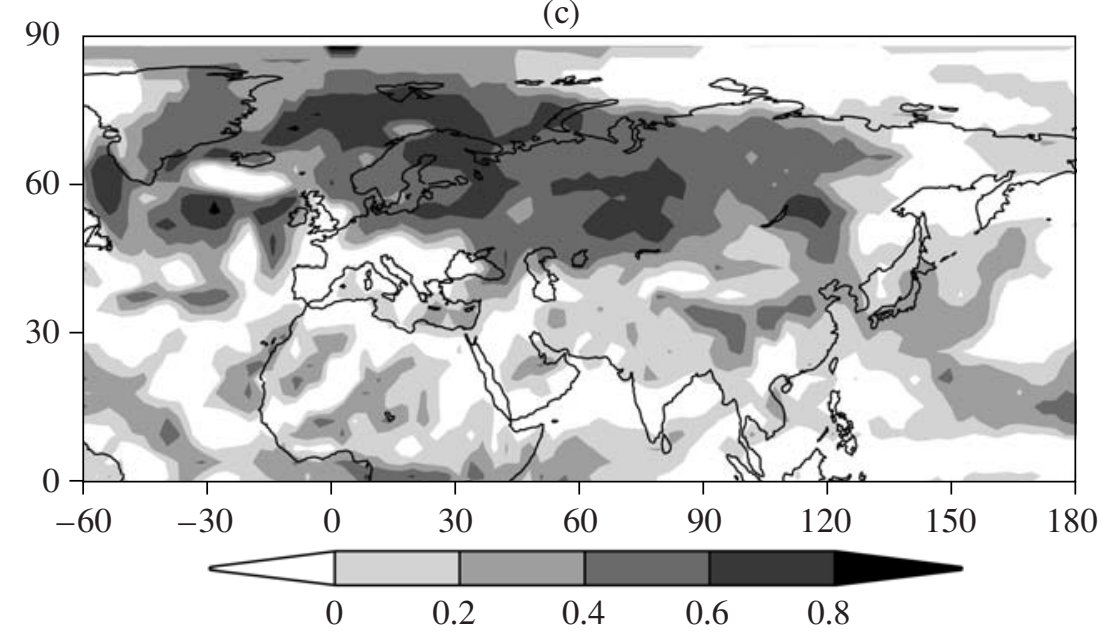

Fig. 1. Spatial distributions of correlation coefficients between long-period variations (20-yr running averaging) in annual mean intensity of the ATHC and seasonal values of surface temperatures (a); pressure at sea level (b), and precipitation (c) in winter (December-February). The minimal correlation coefficient corresponding to the $95 \%$ level of statistical significance is equal to 0.45 . 


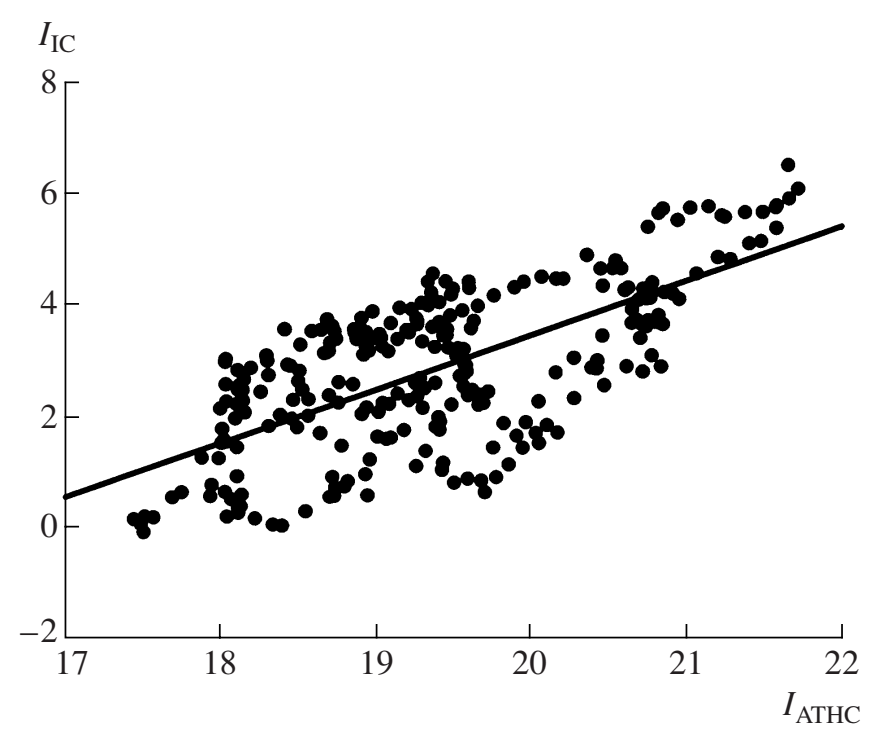

Fig. 2. Intensity of the winter Iceland minimum, $I_{\mathrm{IC}}(\mathrm{hPa})$, as function of annual mean intensity, $I_{\mathrm{ATHC}}(\mathrm{Sv})$ with 20-yr running averaging.

model has a variable spatial resolution from $10 \mathrm{~km}$ near Greenland to $300 \mathrm{~km}$ in the Pacific Ocean and 40 vertical layers. A detailed description of the model and test numerical experiment is presented in [5]. No correction of ocean-atmosphere heat and moisture fluxes was used in the ECHAM5/MPI-OM.

Correlations between variations in the annual mean values of $I$ and the seasonal average fields of $T, P$, and $R$ were analyzed on the basis of numerical calculations for a 500-yr period. Running average values with different intervals of averaging $\Delta \tau$ were used to analyze long-period variations. The greatest correlations were distinguished in the winter period. This is related to the most intense ocean surface-atmosphere and oceancontinent heat fluxes in the cold period of the year owing to the strongest zonal velocities in the troposphere of mid-latitudes and polar latitudes. Figure 1 presents spatial distributions of correlation coefficients $r$ between comparatively long-period variations (with periods of a few decades) of annual mean values of $I$ and seasonal values of $T$ (Fig. 1a), $P$ (Fig. 1b), and $R$ (Fig. 1c) for winter (December-February) at $\Delta \tau=20 \mathrm{yr}$. The minimal correlation coefficient $r$ in Fig. 1 corresponding to $95 \%$ level of statistical significance is equal to 0.45 .

The regions of positive correlation between surface temperature and annual mean intensity of the ATHC dominate in winter in the Northern Hemisphere. Figure 1a shows elongated regions with a high positive correlation between $I$ and the winter surface temperature $T$ over the North Atlantic from the tropical region to the arctic latitudes, over Europe (and south of Europe), and in mid-latitudes in Asia.
A negative correlation between the sea level pressure $P$ and $I$ dominates in the Northern Hemisphere, including middle-high latitudes over Northern Eurasia and high latitudes over the North Atlantic and Arctic Ocean (over the Norwegian and Barents seas) (Fig. 1b). A sufficiently high correlation was found, in particular, in the zones of the influence of the Siberian anticyclonic and Iceland cyclonic ACs.

Positive correlation between precipitations in winter with $I$ was found over Eurasia and North Atlantic at middle-high latitudes (Fig. 1c). According to Fig. 1, the region of significant correlation between the intensity of the ATHC and precipitation generally corresponds to the region of the highest correlation between the intensity of the ATHC and sea surface pressure with some relatively small-scale features (Fig. 1c). It is worth noting that despite the close location to the OST anomalies in the North Atlantic, no significant correlation was found in West Europe for $P$ and $R$. However, the regions of their high correlation spread as a quite wide band from the Norwegian and Barents seas to East Siberia.

According to Fig. 2, a significant correlation (correlation coefficient is 0.7 ) is found between $I$ and the intensity of the Iceland minimum, which is characterized by the $P$ anomaly in the AC with respect to the periphery. An intensification of the Iceland cyclonic AC during intensification of the ATHC is related to the displacement of the trajectories of the North Atlantic cyclones and their intensification. This was found from the NCEP/NCAR reanalysis data in the last $40 \mathrm{yr}$ of the 20th century [12], which is the period of increasing OST in the North Atlantic (a similar tendency is also manifested in the data in [13]).

It is worth noting that the correlation with the intensity of the ATHC in other climatic seasons (in particular, in summer) is lower than in winter. It is important that the strongest variations are prominent in winter in recent decades (based on observations). In winter, when the meridional differences between temperatures at low and high latitudes are greater and the tropospheric circulation is more intense (including those with strong zonal transport at mid-latitudes), larger scale variations in the climatic variables (including temperature anomalies) are better manifested.

When the ATHC intensifies, the temperature in the North Atlantic increases and anomalous heat spreads more effectively in winter to the regions of Europe and Asia due to the zonal transport at mid-latitudes. A pressure decrease in the regions of the Iceland and Siberian ACs facilitates the manifestation of such a tendency. This corresponds to intensification of the cyclonic AC at subpolar latitudes in the North Atlantic. An increase in the pressure gradient between lower and higher latitudes should lead to intensification of the geostrophic wind, i.e., intensification of the heat-and-moisture transport from the Atlantic to Europe with positive anomalies of temperature and precipitation. Of course, the spatial structure of the anomalies of the precipita- 
tion field is much more variable than that of the temperature field. This is reflected in specific features of its correlation with the variations in the ATHC (Fig. 1). Weakening of the winter Siberian anticyclonic AC favors the deep penetration of this influence into the continent and even to the eastern coast of Asia. Winter cyclones, which transport heat and precipitation, penetrate more effectively into the Siberian maximum domain with extremely low temperatures at the surface.

Remote influence of the ATHC on the regions of East Siberia can also be related to the variations in the ice cover of the Arctic Ocean (in particular, the Barents Sea) caused by variations in the oceanic heat influx from the Atlantic $[14,15]$. Variation in the ice cover area modulates intense fluxes of heat and moisture from the sea surface to the atmosphere. Then, the fluxes are transported in the southeastern direction, resulting in the formation of the anomalies of surface temperature and pressure, in particular, in the Siberian maximum zone.

\section{ACKNOWLEDGMENTS}

This work was supported by the Russian Foundation for Basic Research (project nos. 05-05-64907 and 0705-00164), programs of the Russian Academy of Sciences and the Ministry of Science and Education of the Russian Federation (contract nos. 02.515.11.5031 and 02.515.11.5046), the NATO scientific program (Collaborative Linkage Grant 982423), and the INTAS (grant 06-1000014-6556).

\section{REFERENCES}

1. I. I. Mokhov and V. Ch. Khon, Izv. Atmos. Ocean. Phys. 41, 657 (2005) [Izv. Akad. Nauk, Fiz. Atmos. Okeana 41, 723 (2005)].
2. S. S. Lappo, in Investigations of the Processes of the Ocean and Atmosphere Interaction (Moscow, 1984), pp. 125-129 [in Russian].

3. W. G. Broeker, Oceanography 4, 79 (1991).

4. M. Latif, E. Roeckner, M. Botzet, et al., J. Climate 17, 1605 (2004).

5. J. Jungclaus, H. Haak, M. Latif, and U. Mikolajewicz, J. Climate 18, 4013 (2005).

6. T. Martin and E. Ruprecht, Geophys. Res. Lett. 34 L04703 (2007), doi: 10.1029/2006GL028438

7. V. Ch. Khon, M. Latif, I. I. Mokhov, et al., in Research Activities in Atmosphere and Oceanic Modeling (WCRP, Geneva, 2007), WMO/TD No. 1397, pp. 7.5-7.6.

8. I. I. Mokhov, A. Yu. Artamonov, V. A. Bezverkhny, et al., in Research Activities in Atmosphere and Oceanic Modeling (WCRP, Geneva, 2006), WMO/TD No. 1347, pp. 7.23-7.24.

9. Climate Change 2007. The Physical Science Basis: Contribution of Working Group I to the Fourth Assessment Report of the Intergovernmental Panel on Climate Change, Ed. by S. Solomon et al. (Cambridge Univ. Press, Cambridge, 2007).

10. I. I. Mokhov and V. Ch. Khon, Dokl. Earth Sci. 383, 329 (2002) [Dokl. Akad. Nauk 383, 684 (2002)].

11. I. I. Mokhov, V. A. Semenov, and V. Ch. Khon, Izv. Atmos. Ocean. Phys. 39, 106 (2003) [Izv. Akad. Nauk, Fiz. Atmos. Okeana 39, 150 (2003)].

12. S. K. Gulev, O. Zolina, and S. Grigoriev, Clim. Dyn. 17, 795 (2001).

13. G. S. Golitsyn, I. I. Mokhov, M. G. Akperov, and M. Yu. Bardin, Dokl. Earth Sci. 413, 324 (2007) [Dokl. Akad. Nauk 413, 254 (2007)].

14. V. A. Semenov, Dokl. Earth Sci. 418, 135 (2008) [Dokl. Akad. Nauk 418, 246 (2008)].

15. V. A. Semenov, Izv. Atmos. Ocean. Phys. 43, 687 (2007) [Izv. Akad. Nauk, Fiz. Atmos. Okeana 43, 659 (2007)]. 